\title{
Curcumin Decreased Oxidative Stress, Inhibited NF- $\kappa$ B Activation, and Improved Liver Pathology in Ethanol-Induced Liver Injury in Rats
}

\author{
Suchittra Samuhasaneeto, ${ }^{1}$ Duangporn Thong-Ngam, ${ }^{1}$ Onanong Kulaputana, ${ }^{1}$ \\ Doungsamon Suyasunanont, ${ }^{2}$ and Naruemon Klaikeaw ${ }^{3}$ \\ ${ }^{1}$ Department of Physiology, Faculty of Medicine, Chulalongkorn University, Bangkok 10330, Thailand \\ ${ }^{2}$ Department of Dietatic, Faculty of Medicine, Chulalongkorn University, Bangkok 10330, Thailand \\ ${ }^{3}$ Department of Pathology, Faculty of Medicine, Chulalongkorn University, Bangkok 10330, Thailand
}

Correspondence should be addressed to Duangporn Thong-Ngam, thongngam007@yahoo.com

Received 23 February 2009; Accepted 1 May 2009

Recommended by Stelvio M. Bandiera

To study the mechanism of curcumin-attenuated inflammation and liver pathology in early stage of alcoholic liver disease, female Sprague-Dawley rats were divided into four groups and treated with ethanol or curcumin via an intragastric tube for 4 weeks. A control group treated with distilled water, and an ethanol group was treated with ethanol $(7.5 \mathrm{~g} / \mathrm{kg} \mathrm{bw})$. Treatment groups were fed with ethanol supplemented with curcumin ( 400 or $1200 \mathrm{mg} / \mathrm{kg} \mathrm{bw}$ ). The liver histopathology in ethanol group revealed mild-tomoderate steatosis and mild necroinflammation. Hepatic MDA, hepatocyte apoptosis, and NF- $\kappa$ B activation increased significantly in ethanol-treated group when compared with control. Curcumin treatments resulted in improving of liver pathology, decreasing the elevation of hepatic MDA, and inhibition of NF- $\kappa$ B activation. The $400 \mathrm{mg} / \mathrm{kg}$ bw of curcumin treatment revealed only a trend of decreased hepatocyte apoptosis. However, the results of SOD activity, PPAR $\gamma$ protein expression showed no difference among the groups. In conclusion, curcumin improved liver histopathology in early stage of ethanol-induced liver injury by reduction of oxidative stress and inhibition of NF- $\kappa$ B activation.

Copyright ( 2009 Suchittra Samuhasaneeto et al. This is an open access article distributed under the Creative Commons Attribution License, which permits unrestricted use, distribution, and reproduction in any medium, provided the original work is properly cited.

\section{Introduction}

Alcoholic liver disease (ALD) represents a spectrum of clinical illness and morphological changes that range from fatty liver, hepatic inflammation, and necrosis (alcoholic hepatitis) to progressive fibrosis (alcoholic cirrhosis) [1]. Many of the toxic effects of ethanol in the liver have been associated with its metabolism. Ethanol oxidation generates toxic products such as acetaldehyde, and reactive oxygen species result in oxidative stress that initiates apoptosis and cell injury [2-5].

$\mathrm{NF}-\kappa \mathrm{B}$ is a transcription factor which regulates genes involving in inflammation. It is activated by endotoxin, cytokines, and oxidative stress [6]. In unstimulated cells, NF$\kappa \mathrm{B}$ is a heterodimeric complex that is sequestered in the cytoplasm by its interaction with $\mathrm{I} \kappa \mathrm{B}$ family of inhibitors.
When these cells are stimulated, $\mathrm{I} \kappa \mathrm{B}$ is phosphorylated with subsequent release of NF- $\kappa \mathrm{B}$ resulting in the translocation of NF- $\kappa \mathrm{B}$ from the cytoplasm to the nucleus where it activates the expression of target genes $[7,8]$. Activation of NF$\kappa \mathrm{B}$ increased expression of proinflammatory cytokines and chemokines that were key factors in ethanol-induced liver injury rats [9-12].

Peroxisome proliferators activated receptors gamma $(\operatorname{PPAR} \gamma)$ is a family of ligand-activated nuclear transcriptional factor which regulates cell differentiation, apoptosis, lipid metabolism, and inflammation [13]. More recently, decreased expression of PPAR $\gamma$ has been found in rats with alcoholic liver fibrosis. These suggested that PPAR $\gamma$ may play an important role in the development of hepatocellular inflammation, necrosis, and fibrosis in rats with ethanol consumption [14]. 


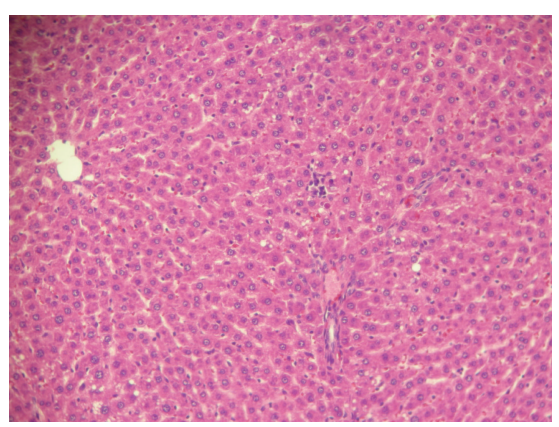

(a)

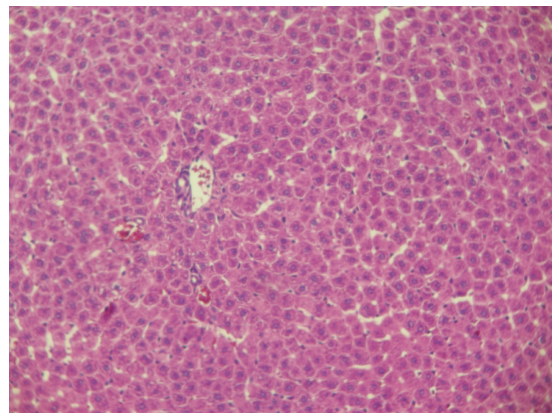

(c)

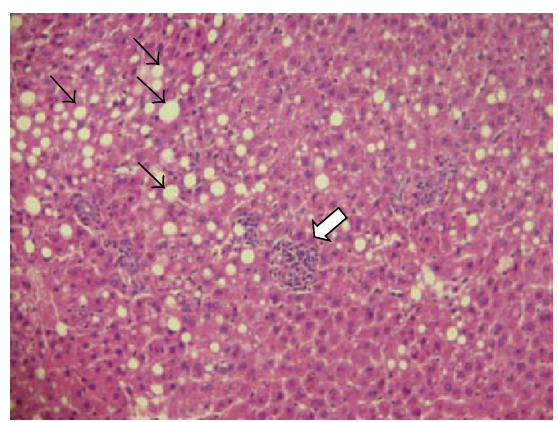

(b)

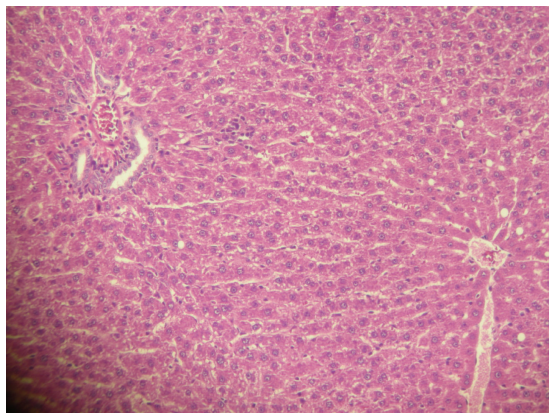

(d)

FIGURE 1: Hematoxylin-eosin-stained liver sections (x400). (a) Control group showed normal liver histopathology. (b) Ethanol-treated group showed steatosis (small arrows) and infiltration of inflammatory cells (block arrow). (c) and (d) Curcumin treatment (400 or 1,200 mg/kg bw a day) showed examples of improvement in steatosis and inflammation.

Curcumin (diferuloylmethane), an antiinflammatory and antioxidant compound, is isolated from the rhizomes of the plant Curcuma longa Linn. Importantly, it has been showed that curcumin suppressed the activation of NF$\kappa \mathrm{B}$ in ethanol-induced liver injury in rats [10]. Activation of PPAR $\gamma$ by curcumin resulted in inhibition of NF- $\kappa$ B transactivating activity and increased expression of PPAR $\gamma$ at both the transcriptional and translational levels in activated hepatic stellate cells (HSCs) [15].

However, it is unclear whether curcumin had any effect in early stage of ethanol-induced liver injury. Therefore, the present study determined the effect of curcumin on early stage of ethanol-induced liver inflammation and improved pathology in rats.

\section{Materials and Methods}

2.1. Animal Preparation. Female Sprague-Dawley rats, weighing 180-220 grams, purchased from the National Laboratory Animal Center, Mahidol University, Salaya, Nakorn pathom, were used. The rats were kept in a controlled temperature room at $25 \pm 1{ }^{\circ} \mathrm{C}$ under standard conditions (12-hour day-night rhythm). All rats were received well care in accordance with the Ethical Committee, Faculty of Medicine, Chulalongkorn University, Thailand.

2.2. Curcumin Preparation. Curcumin in powder form (Cayman Chemical Company, USA) is dissolved in 50\% ethanol that freshly prepared for the experiment.
2.3. Experimental Protocol. All rats were fed with the controlled diet which contained $35 \%$ of energy from fat, $18 \%$ from protein, and $47 \%$ from carbohydrate for 4 weeks ad libitum [16]. They were randomly divided into four experimental groups.

Group 1 (Control, $n=8$ ): rats were fed distilled water $(2.0 \mathrm{~mL})$ orally via an intragastric tube once per day for 4 weeks.

Group 2 (Ethanol, $n=8$ ): rats were fed $50 \%$ ethanol $(7.5 \mathrm{~g} / \mathrm{kg}$ bw a day) orally via an intragastric tube twice a day for 4 weeks.

Group 3 (Ethanol + curI, $n=6$ ): rats were fed curcumin $(200 \mathrm{mg} / \mathrm{kg} \mathrm{bw})$ dissolved in $50 \%$ ethanol $(7.5 \mathrm{~g} / \mathrm{kg}$ bw a day) via intragastric tube twice a day for 4 weeks.

Group 4 (Ethanol + curII, $n=7$ ): rats were fed curcumin $(600 \mathrm{mg} / \mathrm{kg}$ bw) dissolved in $50 \%$ ethanol $(7.5 \mathrm{~g} / \mathrm{kg}$ BW a day $)$ by using intragastric tube twice a day for 4 weeks.

At the end of the study, all rats were sacrificed using intraperitoneal injection of an overdose of thiopental sodium. The abdominal walls were opened, and the whole liver was removed. Three small pieces of livers were collected, frozen in liquid nitrogen, and stored at $-80^{\circ} \mathrm{C}$ for MDA analysis, SOD activity, and PPAR $\gamma$ protein expression. The remaining of liver was fixed in $10 \%$ formalin solution to determine histopathology, NF- $\kappa \mathrm{B}$ activation, and hepatic apoptosis.

2.4. Histopathological Examination. After the liver samples were fixed in $10 \%$ formalin solution at room temperature, 
they were processed by the standard method. Briefly, tissues were embedded in paraffin, sectioned at $5 \mu \mathrm{m}$, and stained with Hematoxylin-Eosin, and then picked up on glass slides for light microscopy. All samples were evaluated by an experienced pathologist who is blinded to the experiment. All fields in each section were examined for grading of steatosis and necroinflammation according to Colantoni et al's criteria [17].

Steatosis was scored as the percentage of parenchymal cells containing fat (micro- or macrosteatosis):

$$
\begin{aligned}
& 0=\text { no parenchymal cells containing fat, } \\
& 1=<20 \% \text { of parenchymal cells containing fat, } \\
& 2=20-39 \% \text { of parenchymal cells containing fat, } \\
& 3=40-50 \% \text { of parenchymal cells containing fat, } \\
& 4=>51 \% \text { of parenchymal cells containing fat. }
\end{aligned}
$$

Inflammation and necrosis were scored by the number of foci of inflammation and necrosis identified under lowpower field of light microscope:

$$
\begin{aligned}
& 0=\text { no inflammation and necrosis, } \\
& 1=1 \text { focus per low-power field of inflammation and } \\
& \text { necrosis, } \\
& 2=2 \text { foci per low-power field of inflammation and } \\
& \text { necrosis, } \\
& 3=3 \text { or more foci per low-power field of inflamma- } \\
& \text { tion and necrosis. }
\end{aligned}
$$

\subsection{Hepatic Malondialdehyde (MDA) Determination. MDA} was assayed by determining the rate of production of thiobarbituric acid-reactive components [18]. One gram of the liver was homogenized in $1.15 \% \mathrm{KCl}$ buffer on ice. An aliquot of $0.2 \mathrm{~mL}$ was mixed with solution containing $20 \%$ acetic acid, $0.8 \%$ thiobarbituric acid, and $8.1 \%$ sodium dodecyl sulfate, heated in water bath at $95^{\circ} \mathrm{C}$ for 60 minutes. The solution was centrifuged for 10 minutes at $4000 \mathrm{rpm}$, and the absorbance of the supernatant fraction was determined at a wavelength of $546 \mathrm{~nm}$. The content of MDA was expressed in terms of $\mathrm{nmol} / \mathrm{mg}$ protein.

2.6. Hepatic Superoxide Dismutase (SOD) Activity. SOD was determined using the method of Winterbourn, in which the light-triggered release of superoxide radicals from riboflavin leads to the formation of a blue complex through reaction with nitroblue tetrazolium [19]. One gram of the liver was homogenized in $0.1 \mathrm{M}$ phosphate buffer $\mathrm{pH} 7.4$ on ice and cleared by centrifugation at $3000 \mathrm{rpm}$ at $4^{\circ} \mathrm{C}$ for 15 minutes. The supernatant fraction was incubated in solution containing $0.067 \mathrm{M}$ phosphate buffer $\mathrm{pH}$ 7.8, 0.1 M EDTA, $1.5 \mathrm{mM}$ NBT and $0.12 \mathrm{mM}$ riboflavin for 10 minutes in an illuminated chamber with an $18 \mathrm{~W}$ fluorescent lamp. Absorbance was recorded at $560 \mathrm{~nm}$, and SOD activity was expressed as units/mg protein.

2.7. Hepatic Apoptosis Determination. Apoptosis was measured by the identification of apoptotic nuclei in sections of liver by fragment end labeling of DNA (Apoptosis detection kit, Chemicon, USA). In brief, endogenous peroxidase activity was inactivated by $3 \%$ hydrogen peroxide $\left(\mathrm{H}_{2} \mathrm{O}_{2}\right)$. The DNA fragments were allowed to bind an antidigoxigenin antibody that was conjugated to a peroxidase. Diaminobenzidine (DAB) was applied to develop dark brown color and then the slides were counterstained with hematoxylin. All fields in each sample were evaluated for positive stained liver cell. The results were expressed as the number of positive stained cells per high-power field.

2.8. Immunohistochemistry for Expression of NF- $\boldsymbol{\kappa} B$ p65 in Liver. The liver sections were deparaffinized with xylene and ethanol for ten minutes. After water washing, sections retrieved the antigen (NF- $\kappa \mathrm{B}$ p65, Santa Cruz, USA) with citrate buffer $\mathrm{pH} 6.0$ in microwave for thirteen minutes. Next, $3 \% \mathrm{H}_{2} \mathrm{O}_{2}$ and $3 \%$ normal horse serum were performed on the slides to block endogenous peroxidase activity for five minutes and blocked nonspecific binding for twenty minutes, respectively. Then, the primary antibody used for NF- $\kappa \mathrm{B}$ p 65 , a polyclonal antibody against the p65 subunit, was applied at a dilution of 1:150 for one hour at room temperature and incubated with the secondary antibody for thirty minutes. When the development of the color with $\mathrm{DAB}$ was detected, the slides were counterstained with hematoxylin.

Under light microscopy, the positive stained cells presented dark brown in nucleus. The results were expressed as the number of positive stained cells per high-power field.

2.9. Western Blot Analysis of PPARy Protein Expression in Liver. Liver sample $(0.1 \mathrm{~g})$ was homogenized in $1 \mathrm{~mL}$ of lysis buffer for 30 minutes on ice and cleared by centrifugation at $12000 \mathrm{rpm}$ for 15 minutes at $4^{\circ} \mathrm{C}$. Protein concentration was assessed by the Lowry method [20]. A $60 \mu \mathrm{g}$ of protein was applied to $10 \%$ SDS-PAGE gel, and the fractionated proteins were transferred to polyvinylidene fluoride membrane. Membrane was blocked in TBST containing 5\% dry nonfat milk for 1 hour and then incubated with PPAR $\gamma$ monoclonal antibodies (1:400, Santa Cruz, USA) overnight at $4{ }^{\circ} \mathrm{C}$. Then washed three times and incubated with secondary antibody, goat antimouse IgG horseradish peroxidase (1:4,000, Cayman, USA) for 1 hour. Protein band was visualized by ECL western blotting system (Amersham, USA). The band densities were normalized by $\beta$-actin using a Scion Image system.

2.10. Data Analysis. All data were presented as means and standard deviation (SD). For comparison among all groups of animals, one way analysis of variance (one-way ANOVA) and Tukey posthoc comparisons were employed. Differences were considered statistically significant at $P<.05$.

\section{Results}

3.1. Histopathological Examination. The histologic appearance of the liver in the control group was normal (Figure 1(a)). In the ethanol-treated group, the histologic 


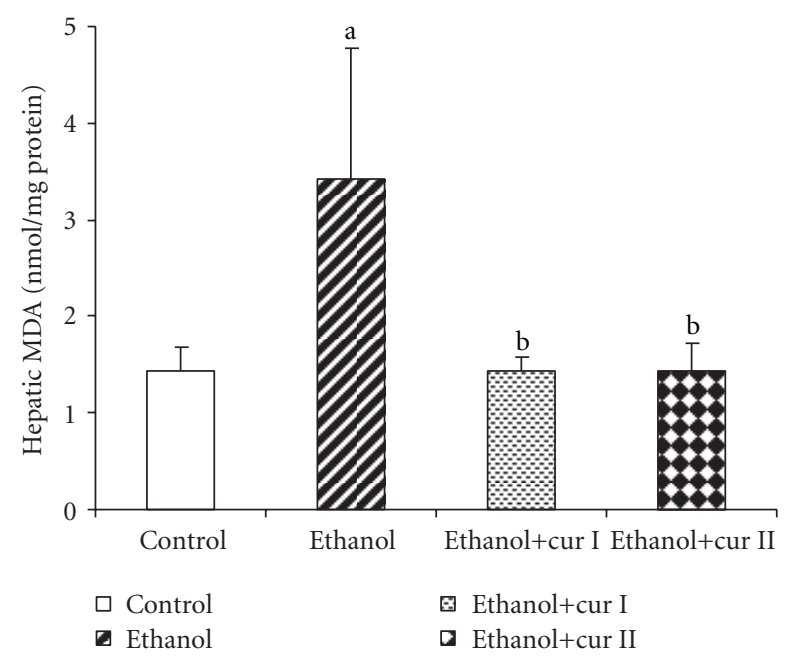

Figure 2: Hepatic MDA levels in all groups. All data are expressed as mean \pm SD. The hepatic MDA levels were significantly higher in the ethanol-treated group (Ethanol) when compared with control group ( $\left.{ }^{a} P<.05\right)$. Two doses of curcumin treatment (Ethanol + curI and Ethanol + curII) decreased significantly hepatic MDA levels when compared with Ethanol ( $\left.{ }^{\mathrm{b}}<.05\right)$.

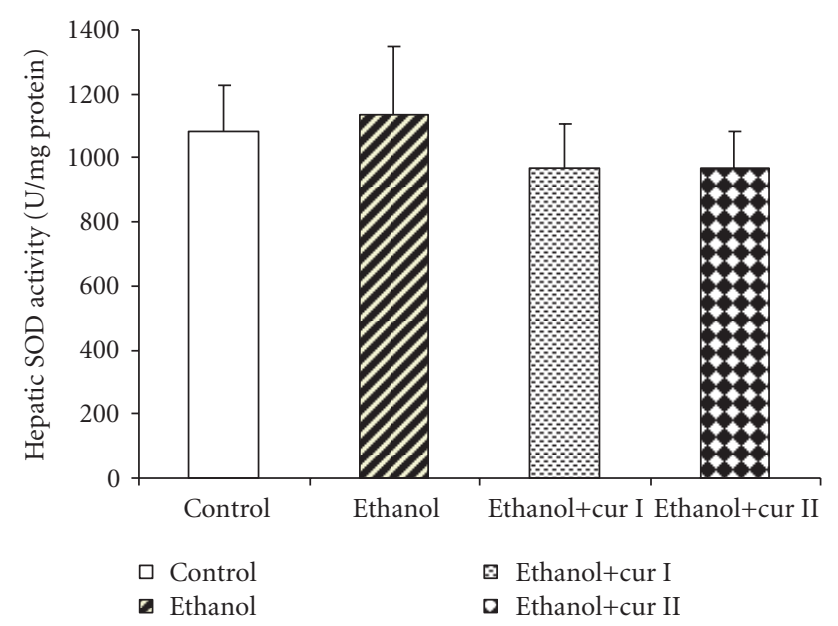

Figure 3: Hepatic SOD activity in all groups. All data are expressed as mean \pm SD. No significant differences were observed among groups.

features showed mild to moderate steatosis and mild necroinflammation (Figure 1(b)). Rats treated with ethanol and curcumin $400 \mathrm{mg} / \mathrm{kg}$ bw a day improved the liver histopathology that showed only mild steatosis but not necroinflammation (Figure 1(c)). The high dose of curcumin treatment $(1,200 \mathrm{mg} / \mathrm{kg}$ bw a day) also improved the liver histopathology that showed mild steatosis and mild necroinflammation (Figure 1(d)). The summary of steatosis and necroinflammation score were shown in Table 1.

3.2. Hepatic MDA Level. The level of hepatic MDA, a marker of lipid peroxidation, increased significantly in ethanoltreated group as compared with control group $(3.42 \pm 1.36$

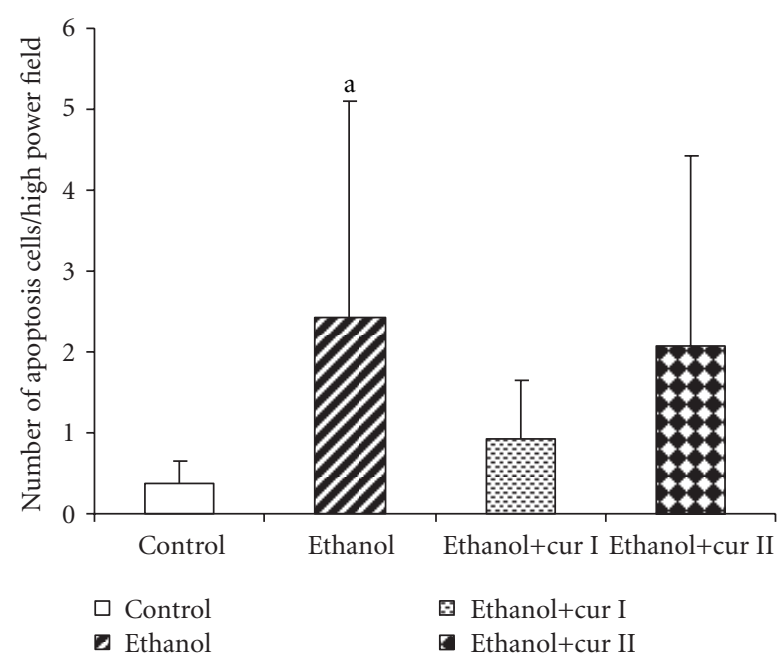

Figure 4: Number of apoptosis cells in all groups. All data are expressed as mean \pm SD. Ethanol-treated group (Ethanol) increased significantly apoptotic cells when compared with control group $\left({ }^{\mathrm{a}} P<.05\right)$.

TABLE 1: Summary of steatosis and necroinflammation score in all groups. Data are expressed as the number of rats exhibiting the grade of steatosis or necroinflammation indicated.

\begin{tabular}{|c|c|c|c|c|c|c|c|c|c|c|}
\hline \multirow{2}{*}{ Group } & \multirow{2}{*}{ Number } & \multicolumn{5}{|c|}{ Steatosis $^{\mathrm{a}}$} & \multicolumn{4}{|c|}{ Necroinflammation $^{b}$} \\
\hline & & 0 & 1 & 2 & 3 & 4 & 0 & 1 & 2 & 3 \\
\hline Control & 8 & 8 & - & - & - & - & 8 & - & - & - \\
\hline Ethanol & 8 & - & 1 & 6 & 1 & - & - & 8 & - & - \\
\hline Ethanol + curI & 6 & 5 & 1 & - & 一 & - & 6 & - & - & - \\
\hline Ethanol + curII & 7 & 4 & 3 & - & - & - & 3 & 4 & - & - \\
\hline
\end{tabular}

${ }^{\text {a The severity of steatosis was grade by the following. } 0=\text { no parenchymal }}$ cells containing fat, $1=<20 \%$ of parenchymal cells containing fat, $2=20$ $39 \%$ of parenchymal cells containing fat, $3=40-50 \%$ of parenchymal cells containing fat, $4=>51 \%$ of parenchymal cells containing fat.

${ }^{\mathrm{b}}$ The severity of necroinflammation was grade by the following. $0=$ no inflammation and necrosis under low-power field, $1=1$ focus per low-power field, $2=2$ foci per low-power field, $3=3$ or more foci per low-power field.

versus $1.44 \pm 0.24 \mathrm{nmol} / \mathrm{mg}$ protein, $P<.05)$. Curcumin treatment (400 or $1,200 \mathrm{mg} / \mathrm{kg}$ bw a day) decreased the elevation of hepatic MDA level significantly when compared with ethanol-treated group $(1.43 \pm 0.14$ versus $3.42 \pm 1.36$ and $1.43 \pm 0.29$ versus $3.42 \pm 1.36 \mathrm{nmol} / \mathrm{mg}$ protein, resp.; $P<.05)$ (Figure 2).

3.3. Hepatic SOD Activity. SOD enzyme converts $\mathrm{O}_{2}{ }^{-}$into a less toxic product. This enzyme is the first line in cell defense against oxidative stress. Our results showed that the level of hepatic SOD activity of the control group was $1081.36 \pm$ $145.01 \mathrm{units} / \mathrm{mg}$ protein, while that of the ethanol-treated group was $1135.86 \pm 209.48$ units/mg protein. In rats treated with ethanol and curcumin ( 400 or $1,200 \mathrm{mg} / \mathrm{kg}$ bw a day), the levels of hepatic SOD activity were $966.28 \pm 139.44$ and $967.84 \pm 116.66$ units/mg protein, respectively. There was no significant difference among groups (Figure 3 ). 


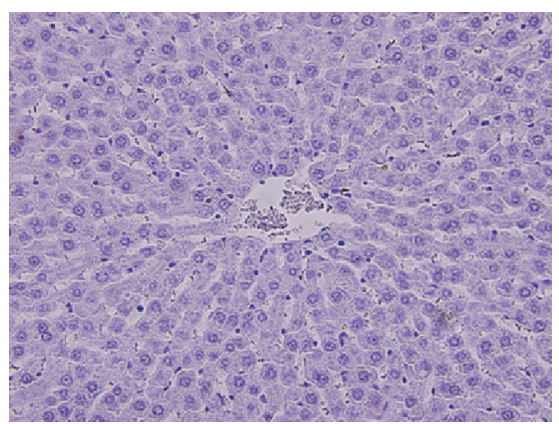

(a)

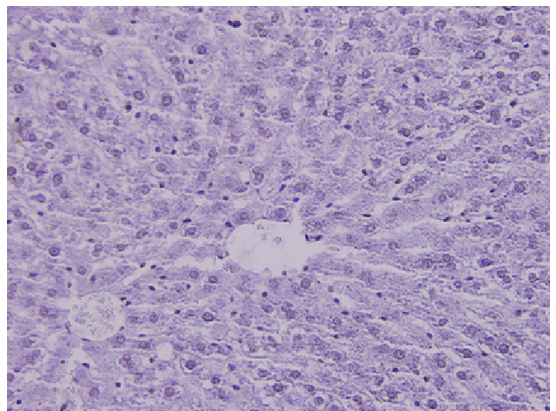

(c)

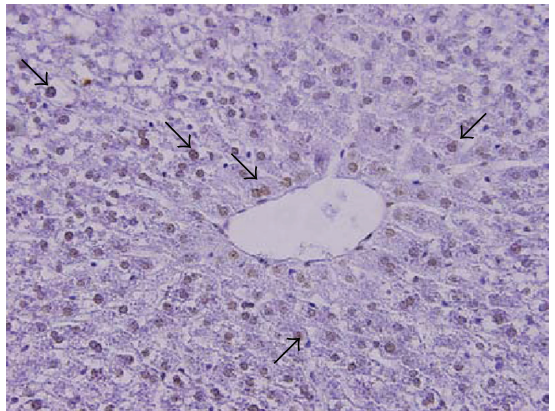

(b)

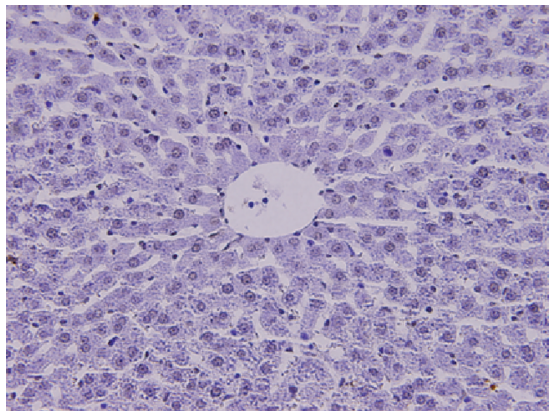

(d)

FIGURE 5: Representative liver sections processed for apoptosis assay by TUNEL reaction (x400). (a) Control group. (b) Ethanol-treated group, the black arrows indicated a TUNEL-positive apoptoic hepatocyte found frequently around central vein. (c) and (d) curcumin treatment (400 or $1,200 \mathrm{mg} / \mathrm{kg}$ bw a day) showed a decrease of apoptotic hepatocytes.

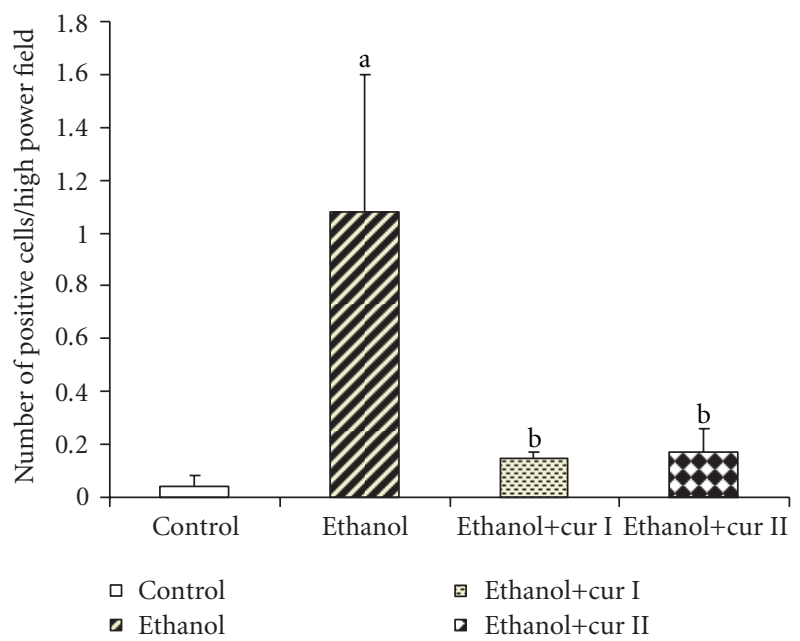

Figure 6: Number of NF- $\kappa$ B p65 positive cells/high-power field in all groups. All data are expressed as mean \pm SD. Ethanol-treated group (Ethanol) increased significantly NF- $\kappa \mathrm{B}$ p 65 positive cells when compared with control group $\left({ }^{a} P<.05\right)$. Two doses of curcumin treatment (Ethanol + curI and Ethanol + curII) decreased significantly NF- $\kappa \mathrm{B}$ p65 positive cells when compared with Ethanol ( $\mathrm{b} P<.05)$.

3.4. Hepatic Apoptosis. Hepatocyte apoptosis was determined by TUNEL assay. The number of apoptotic nuclei in the liver of control group was very low $(0.38 \pm 0.28$ cells/highpower field). In contrast, the numbers of apoptotic cells were observed frequently in centrilobular area in ethanol-treated group when compared with control group $(2.43 \pm 2.68$ versus $0.38 \pm 0.28$ cells/high-power field, $P<.05$ ) (Figures 4 and 5). There was a trend of decreased apoptosis in low dose of curcumin treatment, but the difference did not reach a statistical significance (Figure 4 ).

3.5. Expression of NF- $\kappa B$ p 65 in Liver. The expression of NF$\kappa \mathrm{B}$ p65 in liver was determined by immunohistochemistry. The data of NF- $\kappa \mathrm{B}$ p65 expression in all groups were given in Figure 6. The number of positive stained cells in the liver of ethanol-treated group was significantly higher than control group $(1.08 \pm 0.52$ versus $0.04 \pm 0.04$ cells/highpower field, $P<.05)$. In contrast, curcumin treatment $(400$ or $1,200 \mathrm{mg} / \mathrm{kg}$ bw a day) decreased the number of positive stained cells significantly when compared with ethanoltreated group $(0.15 \pm 0.02$ versus $1.08 \pm 0.52$ and $0.17 \pm 0.09$ versus $1.08 \pm 0.52$ cells/high-power field, resp.; $P<.05)$ (Figures 6 and 7).

3.6. PPARy Protein Expression in Liver. In order to examine the change of PPAR $\gamma$ protein expression in early stage of ethanol-induced liver injury, we measured $\operatorname{PPAR} \gamma$ protein expression in the liver. The PPAR $\gamma$ protein expression in control group was $0.57 \pm 0.19$, and ethanol group was $0.68 \pm 0.16$. Rats treated with ethanol and curcumin (400 or $1,200 \mathrm{mg} / \mathrm{kg}$ bw a day) had $0.44 \pm 0.03$ and $0.54 \pm 0.23$, 


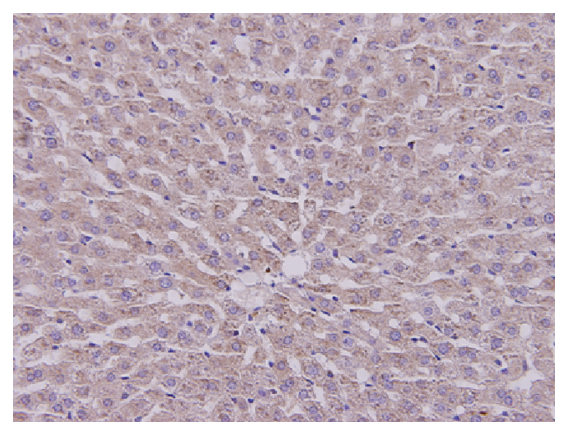

(a)

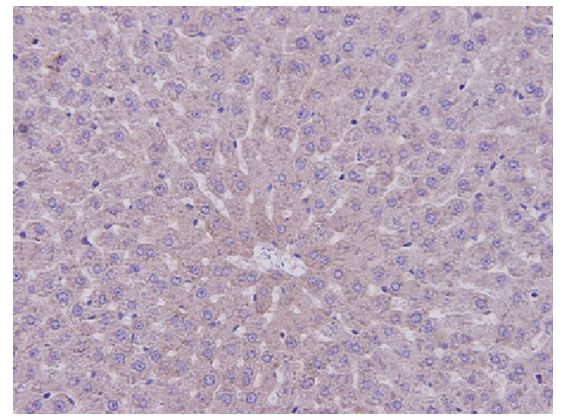

(c)

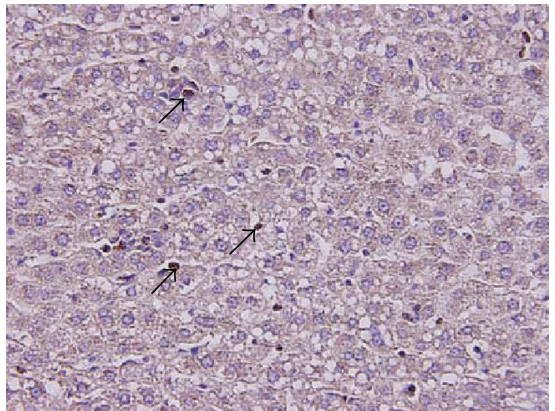

(b)

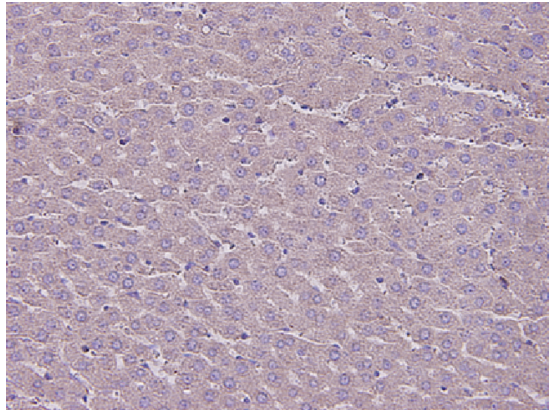

(d)

FIgURE 7: Immunohistochemistry of NF- $\kappa$ B p65 expression in rat liver (x400). (a) Control group. (b) Ethanol-treated group showed NF- $\kappa$ B p65 positive cells in nuclei (black arrow). (c) and (d) curcumin treatment ( 400 or $1,200 \mathrm{mg} / \mathrm{kg}$ bw a day) showed a diminishment of NF- $\kappa \mathrm{B}$ expression in hepatocyte nuclei.

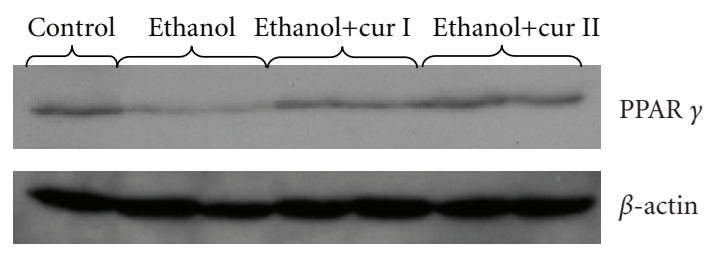

(a)

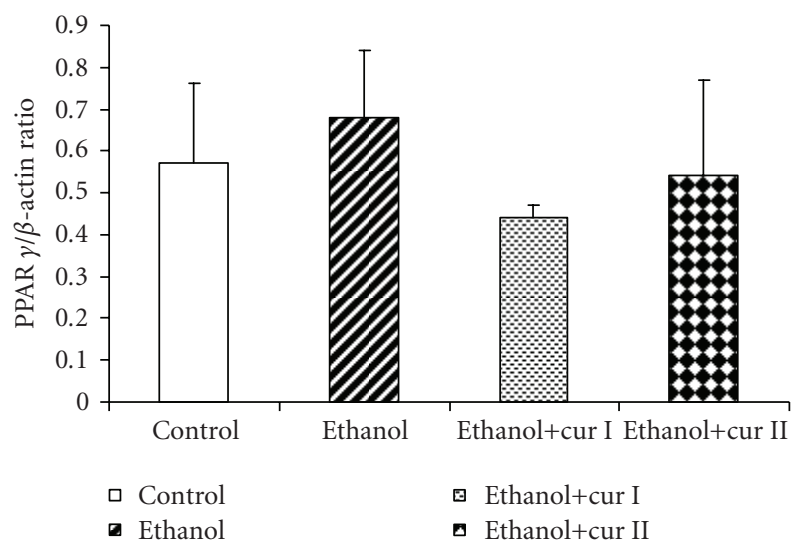

(b)

FIGURE 8: PPAR $\gamma$ protein expression determined by Western blot analysis. (a) represented bands of PPAR $\gamma$ and $\beta$-actin. (b) normalized densitometric ratio of PPAR $\gamma$ to $\beta$-actin.

respectively. These data did not show a significant change in PPAR $\gamma$ protein expression in the liver in all groups (Figure 8).

\section{Discussion}

Ethanol oxidation generates toxic metabolites, free radicals; and induces a state of oxidative stress which contributes to the pathogenesis of ALD. Importantly, oxidation of ethanol through the cytochrome P450 2E1 (CYP 2E1) generates superoxide anion radical and hydrogen peroxide $[2,21$, 22]. These free radicals are capable of damaging many cellular components such as DNA, protein, and lipid [23]. One of the characteristic features of oxidative stress is enhancement of lipid peroxidation. A number of studies have been demonstrated that ethanol intake increased the formation of lipid peroxidation product, such as MDA [2426]. We found that an increase in hepatic MDA level as well as pathological changes were observed in ethanol-treated group.

To counteract this oxidative stress, cells have a variety of antioxidant enzymes, including SOD, catalase, and glutathione peroxidase. SOD catalyzes the rapid removal of superoxide radicals [27]. The effects of chronic ethanol exposure on activity of SOD are controversial, with reports of decrease or no changes $[25,28]$. These studies may reflect variations in experimental design, diet, and duration of ethanol feeding. Decreased SOD activity in ethanol fed rats was associated with enhancement of lipid peroxidation and severe pathology of liver [25]. Our model showed mild histopathology changes in both steatosis and necroinflammation. Therefore, the SOD activity in liver did not change in early ethanol-induced liver injury. 
Oxidative stress can also initiate or amplify inflammation through upregulation of several genes involved in the inflammatory response. One such gene is NF- $\kappa \mathrm{B}$, whose activation results in the upregulation of proinflammatory cytokines [6]. Activation of NF- $\kappa \mathrm{B}$ and upregulation of cytokine production occurred in ethanol-induced liver injury and are associated with lipid peroxidation $[9,10]$. Our study confirmed induction of NF- $\kappa \mathrm{B}$ activation in ethanoltreated group. Curcumin is known as antioxidant and antiinflammatory properties. It is the free radical scavenger and inhibited lipid peroxidation product [29-32]. Evidence was presented that curcumin prevented ethanol-induced liver injury in rats by inhibiting the expression of NF- $\kappa \mathrm{B}-$ dependent genes [10]. Although, a high dose of curcumin treatment $(1,200 \mathrm{mg} / \mathrm{kg} \mathrm{bw})$ was not better than low dose $(400 \mathrm{mg} / \mathrm{kg} \mathrm{bw})$, the present study showed that curcumin improved ethanol-induced liver injury by reduction of oxidative stress and inhibition of NF- $\kappa \mathrm{B}$ activation.

Ethanol-induced liver injury has been linked to oxidative stress caused by the production of reactive oxygen intermediates that cause mitochondrial dysfunction, leading to a release of proapoptotic factors such as cytochrome c that can activate caspases and initiate the apoptotic cascade in hepatocytes [33]. Jin and coworker observed the pathological changes and investigated the correlation of hepatocyte apoptosis with CYP2E1 expression and oxygen free radical in rats with ALD [34]. Using the TUNEL assay, we detected a difference in apoptosis between the control and ethanol-treated group that was similar to human alcoholic hepatitis and experimental rat model of ALD [33-35]. Cells in centrilobular area are low $\mathrm{O}_{2}$ and nutrient supply thus the distribution of apoptotic cells is observed frequently in centrilobular area [36]. In this study curcumin treatment did not detect a difference in hepatocyte apoptosis; however, this was a trend of decreased apoptosis in low does of curcumin treatment.

More recently, decreasing of PPAR $y$ expression was found in alcoholic liver fibrosis rats [14]. This stage showed severe liver injury and HSC activation. In normal liver, HSCs undergo a process known as activation, which upregulate cytokines and growth factor. For instance, platelet-derived growth factor is capable of inhibiting PPAR $y$ expression via mitogen-activated protein kinase-mediated phosphorylation of PPAR $\gamma$ [37]. Also, TNF- $\alpha$, inflammatory cytokine, is known to inhibit PPAR $y$ expression in adipocytes and an early phase of HSC activation in liver fibrosis $[38,39]$, thus alcoholic liver fibrosis rats could decrease PPAR $\gamma$ expression. Our model showed only mild steatosis, necroinflammation, and no HSC activation; therefore, no change of PPAR $\gamma$ protein expression was found in ethanol-treated group. Further studies should be determined roles of PPAR $\gamma$ in different stages of ALD.

In conclusion, our study demonstrated that curcumin, a representative phenolic antioxidant and antiinflammmation, could improve histopathology of liver in early stage of ethanol-induced liver injury by reduction of oxidative stress and inhibition of NF- $\kappa \mathrm{B}$ activation. For hepatocyte apoptosis, curcumin treatment might have a trend of decreased apoptotic cells in ethanol-fed rats.

\section{Acknowledgments}

The authors thank Associate Professor Suthiluk Pathumraj for MDA reagents and Dr. Amornpun Sereemaspun for technical assistance. This study had a financial support from the 90th Anniversary of Chulalongkorn University Fund (Ratchada phiseksomphot Endowment Fund) and Grant of Ratchada phiseksomphot, Faculty of Medicine, Chulalongkorn University, Bangkok, Thailand.

\section{References}

[1] S. Tome and M. R. Lucey, "Review article: current management of alcoholic liver disease," Alimentary Pharmacology and Therapeutics, vol. 19, no. 7, pp. 707-714, 2004.

[2] S. K. Das and D. M. Vasudevan, "Alcohol-induced oxidative stress," Life Sciences, vol. 81, no. 3, pp. 177-187, 2007.

[3] C. S. Lieber, "Pathogenesis and treatment of alcoholic liver disease: progress over the last 50 years," Roczniki Akademii Medycznej w Białymstoku, vol. 50, pp. 7-20, 2005.

[4] C. S. Lieber, "Alcohol and the liver: metabolism of alcohol and its role in hepatic and extrahepatic diseases," Mount Sinai Journal of Medicine, vol. 67, no. 1, pp. 84-94, 2000.

[5] C. A. Casey, A. A. Nanji, A. I. Cederbaum, M. Adachi, and T. Takahashi, "Alcoholic liver disease and apoptosis," Alcoholism: Clinical and Experimental Research, vol. 25, no. 5, pp. 49S-53S, 2001.

[6] H. L. Pahl, "Activators and target genes of Rel/NF- $\kappa$ B transcription factors," Oncogene, vol. 18, no. 49, pp. 6853-6866, 1999.

[7] Y. Yamamoto and R. B. Gaynor, "Therapeutic potential of inhibition of the NF- $\kappa \mathrm{B}$ pathway in the treatment of inflammation and cancer," Journal of Clinical Investigation, vol. 107, no. 2, pp. 135-142, 2001.

[8] T. D. Gilmore, "The Rel/NF- $\kappa \mathrm{B}$ signal transduction pathway: introduction," Oncogene, vol. 18, no. 49, pp. 6842-6844, 1999.

[9] A. A. Nanji, K. Jokelainen, A. Rahemtulla, et al., "Activation of nuclear factor $\kappa \mathrm{B}$ and cytokine inbalance in experimental alcoholic liver disease in the rat," Hepatology, vol. 30, no. 4, pp. 933-943, 1999.

[10] A. A. Nanji, K. Jokelainen, G. L. Tipoe, A. Rahemtulla, P. Thomas, and A. J. Dannenberg, "Curcumin prevents alcoholinduced liver disease in rats by inhibiting the expression of NF$\kappa \mathrm{B}$-dependent genes," American Journal of Physiology, vol. 284, no. 2, pp. G321-G327, 2003.

[11] K. Jokelainen, L. A. Reinke, and A. A. Nanji, "NF- $\kappa$ B activation is associated with free radical generation and endotoxemia and precedes pathological liver injury in experimental alcoholic liver disease," Cytokine, vol. 16, no. 1, pp. 36-39, 2001.

[12] G.-J. Yuan, X.-R. Zhou, Z.-J. Gong, P. Zhang, X.-M. Sun, and S.-H. Zheng, "Expression and activity of inducible nitric oxide synthase and endothelial nitric oxide synthase correlate with ethanol-induced liver injury," World Journal of Gastroenterology, vol. 12, no. 15, pp. 2375-2381, 2006.

[13] K. L. Houseknecht, B. M. Cole, and P. J. Steele, "Peroxisome proliferator-activated receptor gamma $(\operatorname{PPAR} \gamma)$ and its ligands: a review," Domestic Animal Endocrinology, vol. 22, no. 1, pp. 1-23, 2002.

[14] C.-Y. Zhao, L.-L. Jiang, L. Li, Z.-J. Deng, B.-L. Liang, and J.-M. Li, "Peroxisome proliferator activated receptor- $\gamma$ in pathogenesis of experimental fatty liver disease," World Journal of Gastroenterology, vol. 10, no. 9, pp. 1329-1332, 2004. 
[15] J. Xu, Y. Fu, and A. Chen, "Activation of peroxisome proliferator-activated receptor- $\gamma$ contributes to the inhibitory effects of curcumin on rat hepatic stellate cell growth," American Journal of Physiology, vol. 285, no. 1, pp. G20-G30, 2003.

[16] N. Enomoto, S. Yamashina, H. Kono, et al., "Development of a new, simple rat model of early alcohol-induced liver injury based on sensitization of Kupffer cells," Hepatology, vol. 29, no. 6, pp. 1680-1689, 1999.

[17] A. Colantoni, R. Idilman, N. De Maria, et al., "Hepatic apoptosis and proliferation in male and female rats fed alcohol: role of cytokines," Alcoholism: Clinical and Experimental Research, vol. 27, no. 7, pp. 1184-1189, 2003.

[18] H. Ohkawa, N. Ohishi, and K. Yagi, "Assay for lipid peroxides in animal tissues by thiobarbituric acid reaction," Analytical Biochemistry, vol. 95, no. 2, pp. 351-358, 1979.

[19] C. C. Winterbourn, R. E. Hawkins, M. Brian, and R. W. Carrell, "The estimation of red cell superoxide dismutase activity," Journal of Laboratory and Clinical Medicine, vol. 85, no. 2, pp. 337-341, 1975.

[20] O. H. Lowry, N. J. Rosebrough, and A. L. Farr, "Protein measurement with the folin phenol reagent," The Journal of Biological Chemistry, vol. 193, pp. 265-273, 1951.

[21] D. A. Brenner and S. Sigmund, "Pathogenesis of alcoholic hepatitis," Journal of Gastroenterology and Hepatology, vol. 19, pp. S229-S235, 2004.

[22] C. S. Lieber, "Microsomal ethanol-oxidizing system (MEOS): the first 30 years (1968-1998): a review," Alcoholism: Clinical and Experimental Research, vol. 23, no. 6, pp. 991-1007, 1999.

[23] L. Gaté, J. Paul, G. N. Ba, K. D. Tew, and H. Tapiero, "Oxidative stress induced in pathologies: the role of antioxidants," Biomedicine \& Pharmacotherapy, vol. 53, no. 4, pp. 169-180, 1999.

[24] H. Rouach, V. Fataccioli, M. Gentil, S. W. French, M. Morimoto, and R. Nordmann, "Effect of chronic ethanol feeding on lipid peroxidation and protein oxidation in relation to liver pathology," Hepatology, vol. 25, no. 2, pp. 351-355, 1997.

[25] R. Polavarapu, D. R. Spitz, J. E. Sim, et al., "Increased lipid peroxidation and impaired antioxidant enzyme function is associated with pathological liver injury in experimental alcoholic liver disease in rats fed diets high in corn oil and fish oil," Hepatology, vol. 27, no. 5, pp. 1317-1323, 1998.

[26] E. A. Meagher, O. P. Barry, A. Burke, et al., "Alcohol-induced generation of lipid peroxidation products in humans," Journal of Clinical Investigation, vol. 104, no. 6, pp. 805-813, 1999.

[27] J. Chaudier and R. Ferrari-Iliou, "Intracellular antioxidants: from chemical to biochemical mechanisms," Food and Chemical Toxicology, vol. 37, no. 9-10, pp. 949-962, 1999.

[28] S.-C. Yang, C.-C. Huang, J.-S. Chu, and J.-R. Chen, "Effects of $\beta$-carotene on cell viability and antioxidant status of hepatocytes from chronically ethanol-fed rats," British Journal of Nutrition, vol. 92, no. 2, pp. 209-215, 2004.

[29] N. Sreejayan and M. N. A. Rao, "Free radical scavenging activity of curcuminoids," Arzneimittel-Forschung, vol. 46, no. 2, pp. 169-171, 1996.

[30] N. Sreejayan and M. N. A. Rao, "Nitric oxide scavenging by curcuminoids," Journal of Pharmacy and Pharmacology, vol. 49, no. 1, pp. 105-107, 1997.

[31] A. C. Reddy and B. R. Lokesh, "Effect of curcumin and eugenol on iron-induced hepatic toxicity in rats," Toxicology, vol. 107, no. 1, pp. 39-45, 1996.
[32] E.-J. Park, C. H. Jeon, G. Ko, J. Kim, and D. H. Sohn, "Protective effect of curcumin in rat liver injury induced by carbon tetrachloride," Journal of Pharmacy and Pharmacology, vol. 52, no. 4, pp. 437-440, 2000.

[33] S. Natori, C. Rust, L. M. Stadheim, A. Srinivasan, L. J. Burgart, and G. J. Gores, "Hepatocyte apoptosis is a pathologic feature of human alcoholic hepatitis," Journal of Hepatology, vol. 34, no. 2, pp. 248-253, 2001.

[34] W.-P. Jin, X.-Q. Quan, F.-P. Meng, X.-D. Cui, and H.-J. Piao, "Relationship among hepatocyte apoptosis, P450 2E1 and oxidative stress in alcoholic liver disease of rats," Zhongguo Wei Zhong Bing Ji Jiu Yi Xue, vol. 19, no. 7, pp. 419-421, 2007.

[35] I. V. Deaciuc, N. B. D’Souza, W. J. S. de Villiers, et al., "Inhibition of caspases in vivo protects the rat liver against alcohol-induced sensitization to bacterial lipopolysaccharide," Alcoholism: Clinical and Experimental Research, vol. 25, no. 6, pp. 935-943, 2001.

[36] M. H. Ross, G. I. Kaye, and W. Pawlina, Histology: A Text and Atlas, Lippincott William \& Wilkins, Philadelphia, Pa, USA, 2003.

[37] A. Galli, D. Crabb, D. Price, et al., "Peroxisome proliferatoractivated receptor $\gamma$ transcriptional regulation is involved in platelet-derived growth factor-induced proliferation of human hepatic stellate cells," Hepatology, vol. 31, no. 1, pp. 101-108, 2000.

[38] T. Tanaka, H. Itoh, K. Doi, et al., "Down regulation of peroxisome proliferator-activated receptor $\gamma$ expression by inflammatory cytokines and its reversal by thiazolidinediones," Diabetologia, vol. 42, no. 6, pp. 702-710, 1999.

[39] T. Miyahara, L. Schrum, R. Rippe, et al., "Peroxisome proliferator-activated receptors and hepatic stellate cell activation," The Journal of Biological Chemistry, vol. 275, no. 46, pp. 35715-35722, 2000. 


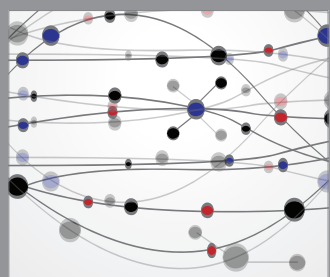

The Scientific World Journal
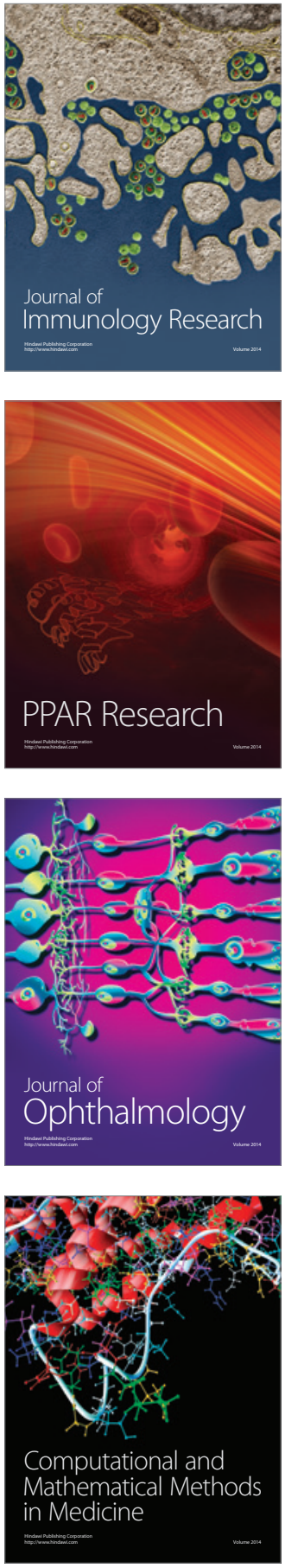

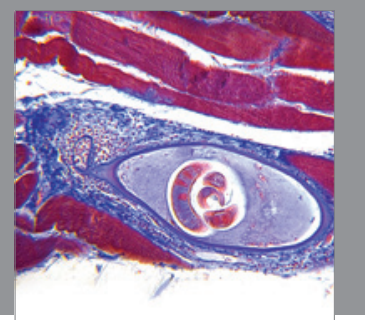

Gastroenterology

Research and Practice
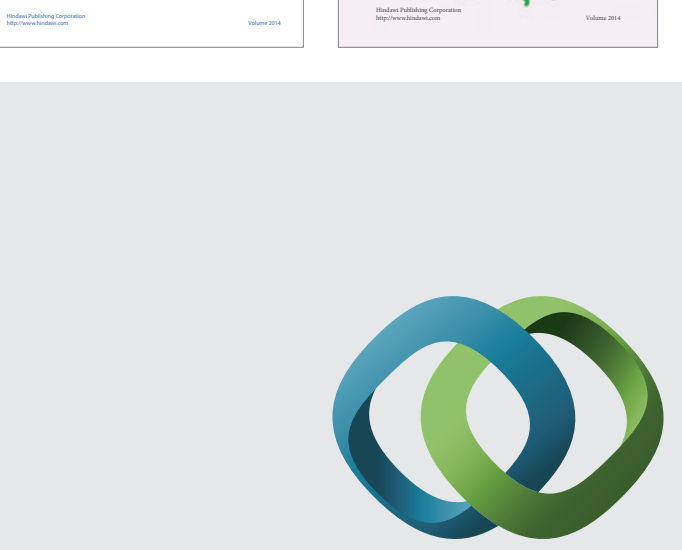

\section{Hindawi}

Submit your manuscripts at

http://www.hindawi.com
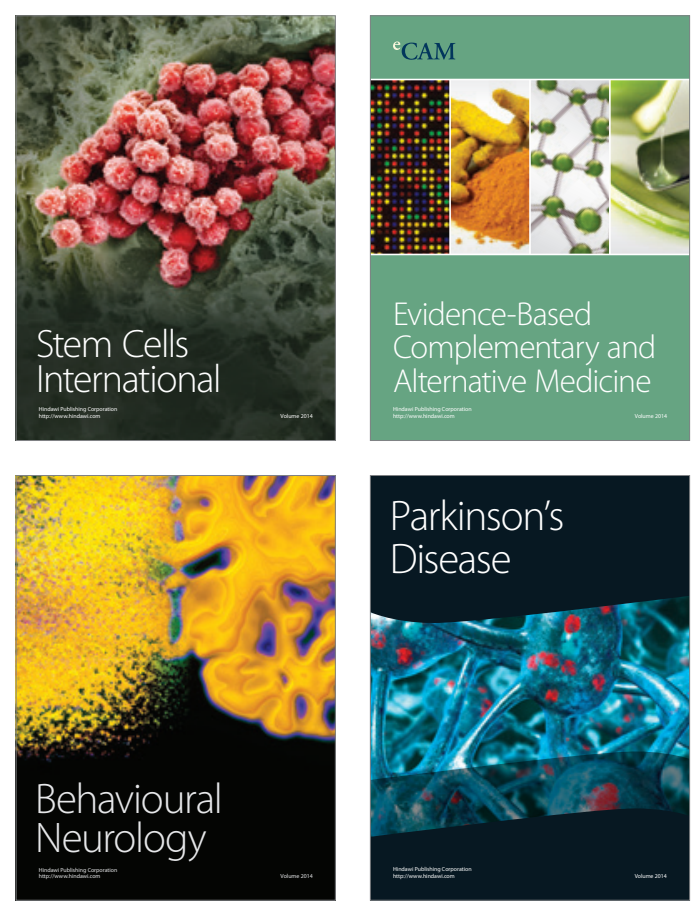

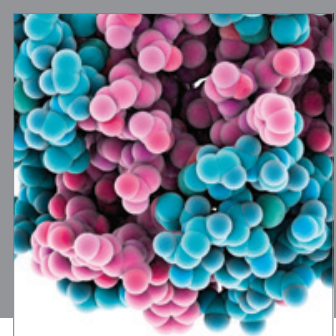

Journal of
Diabetes Research

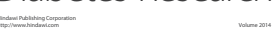

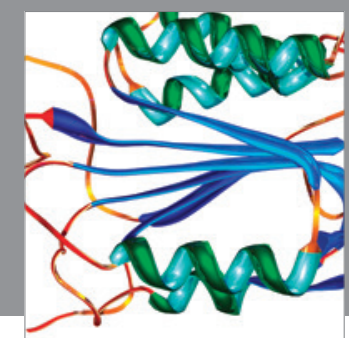

Disease Markers
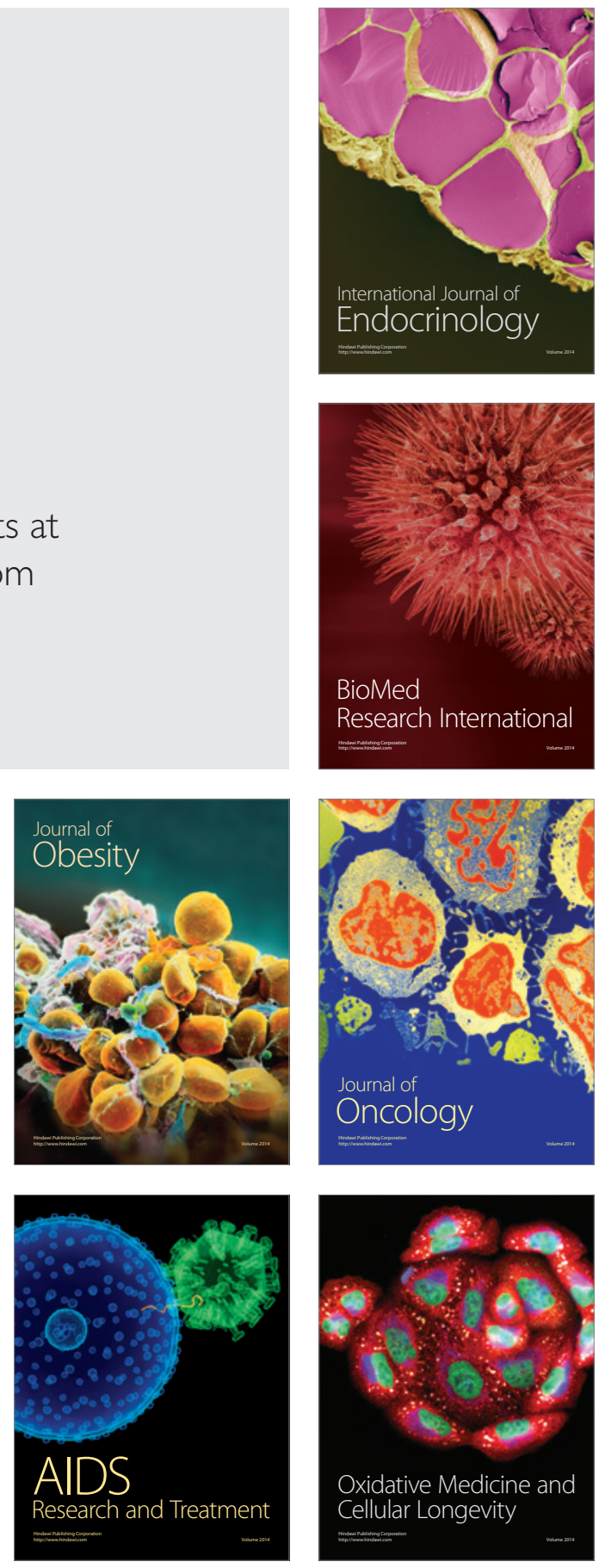